\title{
Cathepsin B is a Negative Regulator in Pulmonary Aspergillosis
}

\author{
Ashwani Mittal, TK Mandal, Rajat Bindal, and Rajesh Dabur
}

\begin{abstract}
Lysosomal cysteine proteases play important roles in our immune-system by processing pathogens but their involvement in fungal mediated diseases remains unknown. In this study with the help of using various techniques such as immunoblotting, enzyme activity profile and ELISA, we observed that cysteine proteases (cathepsin B, L and C) are involved in fungal disease progression. In the mice model of pulmonary aspergillosis, cathepsin (CP)B and CPL activities were observed significantly high while the activity level for CPC was found low. Conversely, treatment of these infected mice with antifungal compounds showed statistically decreases in the activity of CPB $(p<0.05)$ without significant change in CPL and CPC activities, demonstrating CPB role in fungal infection. Notably, altered in the cytokines levels i.e., decreased in IL-4 and increased in IFN- $\square$ in antifungal treated mice further support the resistant effect of antifungal compounds to fungal infection. Importantly, this alteration in cytokines levels is similar to CPB activity profile additionally depicts the regulatory effect of this protease in fungal infection. The involvement of lysosome in this process was confirmed by a lysosomal marker i.e., acid phosphatase. Present study reveals a novel interaction between cysteine protease and pulmonary aspergillosis and illustrates a possible negative role of CPB in fungal infection, due to that it could act as an important therapeutic target and early biomarker for this disease.
\end{abstract}

Index Terms-A. fumigatus, Cathepsins, Antifungal compounds.

\section{INTRODUCTION}

Aspergillus fumigatus is an opportunistic pathogen which can cause a life threatening invasive aspergillosis in immunocompromised patients. The respiratory tract is general portal for entry of A. fumigatus which responsible for major complication in AIDS, bone marrow transplantation and other immunocompromised patients [1, 2]. Its management is hampered by increased incidence and severity of adverse reactions to standard therapies [3]. The high incidence of aspergillosis in chronic granutomatous disease showed the importance of phagocytes in resistance to aspergilli. Cathepsin B and L are highly active enzymes and important for phagocytosis [4]. The increased cysteine

Manuscript received June 15, 2011; revised June 28, 2011.

Ashwani Mittal, Biochemistry Department, Kurukshetra University, Kurukshetra, Haryana - 136119 (e-mail: amittal@kuk.ac.in)

TK Mandal, Regional Research Institute (Ay), (Central Council for Research in Ayurveda and Siddha), Nehru Garden, Kothrud, Pune - 411 038 (e-mail: drmandaltk@yahoo.com)

Rajat Bindal, Biotechnology Department, Seth Jai Parkash Mukund Lal, Institute of Engg. \& Technology, Radaur, Kurukshetra University, Kurukshetra, Haryana - 136119 (e-mail: rajat.rickey@gmail.com)

Rajesh Dabur, Regional Research Institute (Ay), (Central Council for Research in Ayurveda and Siddha), Nehru Garden, Kothrud, Pune - 411 038 (Tel No: + (912025383138); fax: +(912025386715). e-mail: rajeshdabur@yahoo.com. protease activities have been reported in a number of lung diseases [5].Cysteine proteases (CP), acts as endopeptidases, are mainly involved in intracellular protein degradation. These enzymes are synthesized as inactive precursors and are regulated by several inhibitors and or by $\mathrm{pH}$, for their lytic effects [6]. They are optimally active in the slightly acidic milieu found in lysosomes. On the tissue surface, they can degrade foreign proteins and the extracellular matrix. CPs also participates in proteolytic cascades which can lead to pathological damage, and facilitate the penetration of tissues by foreign cells. Additionally, cysteine proteases in lysosomes play another important role in the functional differentiation of MHC class II-restricted CD4+ $\mathrm{T}$ cells. Furthermore, MHC class II antigen presentation is under the control of the cytokines, especially IFN- $\gamma[7,8]$ which is known to potentiate the antifungal activity of macrophages. While, other cytokines such as IL4 helps in proliferating fungal infection explains the beneficial or deleterious effect of cytokines on fungal infection [9]. In recent years, various approaches have been made to eradicate the aspergillosis including the identification of novel antifungal compounds from natural resources. Our group also identified and isolated 2- $(3,4-$ dimethyl- 2,5 - dihydro - $1 \mathrm{H}$ - pyrrole - 2 -yl)-1methylethyl pentanoate (DHP), a novel antifungal compound, from Datura metel [10] which is active at both in vivo and in vitro conditions. From the above fact and also from many published evidences it was found that cysteine protease activity not only increased abruptly very high in various pathological conditions but also has some correlation with macrophages/phagocytes. Nevertheless we didn't find any relationship between enzymes and diseases mediated by fungal infection. Therefore, we hypothesized a relationship between cathepsins and A. fumigates mediated diseases. In the present study, an attempt has been made to study the alterations in the activities of cysteine protease in mice model of aspergillosis and also studied their involvement in the disease progression and healing processes.

\section{MATERIALS AND METHODS}

\section{A. Chemicals}

The - $\beta$-naphthylamide, -4-methoxy- $\beta$-naphthylamide substrates like Z-Phe-Arg-4m $\beta N A$, Z-Arg-Arg-4m $\beta N A$, Gly-Arg--4m $\beta N A$, Leu-4m $\beta N A$ and $\beta$-naphthylamine and 4-methoxy- $\beta$-naphthylamine were purchased from Bachem Feinchemikalein AG, Switzerland. Fast Garnet GBC and Amphotericin B (AmpB) were procured from SigmaAldrich, USA. DHP was purified from Datura metel [11] and used as an antifungal compound AmpB. Cathepsin B 
(G60) and cathepsin L antibodies were purchased from Cell Signaling Tech (USA) and Lifespan Biosciences, Inc (USA) respectively.

\section{B. Pathogen cultivation and Inoculum preparation}

Clinical isolate of A fumigatus (190/96) obtained from Vallabhbhai Patel Chest Institute, Delhi, India, was used along with standard strain (ITCC 4517, obtained from IARI, Delhi, India). Organism was grown on Sabouraud dextrose agar (Merck) plated at $37^{\circ} \mathrm{C}$ for 4 days. The conidia were collected from the culture plates using PBS ( $\mathrm{pH}$ 7.2) containing $0.05 \%$ Tween 80 (Sigma) and the suspension was filtered through sterile glass wool. The conidia were pelleted by centrifugation at $2000 \mathrm{rpm}$ and re-suspended in PBS ( $\mathrm{pH} \mathrm{7.2).} \mathrm{The} \mathrm{number} \mathrm{of} \mathrm{conidia} \mathrm{was} \mathrm{counted} \mathrm{and}$ adjusted to $1 \times 10^{8}$ conidia/ml using hemocytometer. The viability of the conidia was determined by plating the dilutions of suspensions on Sabouraud dextrose agar.

\section{Groups of animals and treatment}

Ethical clearance was obtained from institutional ethics committee for the use of animals. Animals were divided into five groups of 9 animals in each group. The groups were designated as 1-5 (Table 1). Three days prior to infection with conidia, mice (group no 2 to 5) were injected subcutaneously with 3 doses $(250.0 \mathrm{mg} / \mathrm{kg} /$ day $)$ of cortisone acetate in $400.0 \mu \mathrm{l}$ of PBS. On the infection day, each mouse received approximately $2 \times 10^{7}$ conidia by nasal instillation of a single droplet of conidial suspension. Animals of groups no 3-5 were infected with A. fumigatus conidia [12]. Groups 4 and 5 were treated with six doses of antifungal compounds i.e. DHP and AmpB of 250 and 3.0 $\mathrm{mg} / \mathrm{kg}$ body weight/day respectively [10]. The mice of group 1 received only PBS and acted as wild-type control group (WT). Group 2 animal were treated with cortisone only and used as a negative control (NC) while group 3 animals initially treated with cortisone and then infected with $A$. fumigatus, were used as positive control (also called infected group, I).

\section{Tissue preparation}

Animals were sacrificed on $7^{\text {th }}$ day and lungs were isolated in aseptic conditions. Lysosomal fraction was prepared (per gram wet tissue weight) in $0.1 \mathrm{M}$ sodium acetate buffer, pH 5.5 containing $0.2 \mathrm{M} \mathrm{NaCl}$ and $1 \mathrm{mM}$ EDTA, as described by Cohen et al. 2005 [13].

\section{E. Assay for $C P B, C P L$ and $C B C$}

The activity for enzymes cathepsin $\mathrm{B}, \mathrm{L}$ and $\mathrm{C}$ were carried out using their specific substrates i.e. Z-Arg-Arg4m $\beta$ NA (12.9 $\mu \mathrm{mole} / \mathrm{ml}$ DMSO) [14], Z-Phe-Arg-4m $\beta \mathrm{NA}$ (9.27 $\mu \mathrm{mole} / \mathrm{ml}$ DMSO) $[15,16]$ and Gly-Arg-4m $\beta \mathrm{NA}$ (2.17 $\mu \mathrm{mole} / \mathrm{ml} \mathrm{DMSO})$ [17] respectively. The activity units have been expressed as number of picomoles of -4methoxy- $\beta$-naphthylamine or $\beta$-naphthylamine liberated per min per ml enzyme solution at $37^{\circ} \mathrm{C}$.

\section{F. Cytokines profile}

Levels of IL-4 and IFN- $\gamma$ in the blood samples of each animal group were determined by performing enzyme linked immune sorbent assay (ELISA) in immunoplates (Nunc, Maxisorb). The kit for the estimation of IL-4 and
IFN- $\gamma$ were purchased from Pharmingen and ELISA (enzyme linked immunosorbent assay) was performed as per the manufacturer's instructions. The OD was read at 490 $\mathrm{nm}$ in an automated ELISA reader (Molecular Devices, Spectra Max 190).

\section{G. Assay of Acid Phosphates}

Acid phosphatase assay was performed according to the method of Shiloko and Tappel [18]. Briefly, lung lysosomal fraction was incubated with $32 \mathrm{mM}$ p-nitrophenyl phosphate (PNPP, disodium salt) in $0.2 \mathrm{M}$ sodium acetate buffer $\left(\mathrm{pH} \mathrm{5.5)}\right.$ for $15 \mathrm{~min}$ at $37^{\circ} \mathrm{C}$. The reaction was stopped with $0.16 \mathrm{M}$ Tris- $\mathrm{HCl}(\mathrm{pH} 8.5)$ containing $0.06 \mathrm{M}$ $\mathrm{K}_{2} \mathrm{HPO}_{4}$. The reaction product was measured at $420 \mathrm{~nm}$.

\section{H. Western blotting}

Lung tissue was homogenized in lysis buffer A $(50 \mathrm{mM}$ Tris-Cl, pH 8.0, $200 \mathrm{uM} \mathrm{NaCl}, 50 \mathrm{mM} \mathrm{NaF}, 0.3 \%$ Nonidet P-40, $2 \mathrm{mg} / \mathrm{ml}$ leupeptin, $2 \mathrm{mg} / \mathrm{ml}$ aprotinin, phenylmethyl sulfonylfluoride (PMSF), $0.5 \mathrm{mg} / \mathrm{ml}$ benzamidine, $1 \mathrm{mM}$ dithiothreitol, and $1 \mathrm{mM}$ sodium orthovanadate) and clarified by centrifugation as described by Goyal et al with slight modifications [19]. Lung extracts was normalized based on the amount of protein using the Lowry's method [20]. To check levels of cathepsin B and L, $100 \mathrm{ug}$ protein extracts from each sample was separated via $12 \%$ SDSPAGE, transferred to a nitrocellulose membrane, and immunoblot with the cathepsin specific antibody. A 1:500 dilution was used for both primary antibodies (cathepsin B and L) and 1:1000 dilution was used for secondary antibodies. The same blots were stripped and blotted for total b-actin (1:1000, Cell Signaling Technology, USA). The bands were detected with enhanced chemiluminescence using a Chemilmager (Chemidoc, BioRad). Results was analysed and quantified by using Image $\mathrm{J}$ software $(\mathrm{NIH}$, USA).

\section{Statistical Analysis}

Results are expressed as mean \pm S.D. The Student's $t$-test or ANOVA was used to compare quantitative data populations with normal distributions and equal variance. A value of $p<0.05$ was considered statistically significant unless otherwise specified.

\section{RESULTS}

\section{A. Optimum level of CPL in infected mice}

To examine any correlation between cathepsins and pulmonary aspergillosis, A. fumigates infected mice were sacrificed every day after infection and lung tissue was collected to study the activity level of cathepsins. Interestingly, as shown in fig 1, a regular increase in the CPL activity was observed till $6^{\text {th }}$ day and after then it starts decreasing gradually. To prove further this correlation between cathepsins and fungal infection, we made five mice groups in presence or absence of antifungal compounds (Table 1, Fig 2-3) and studied the cathepsins and cytokines profiles. Since CPL activity was observed optimum at $6^{\text {th }}$ day therefore, sixth day was selected to sacrifice all the groups of mice and thereafter all experiments were performed. 


\section{B. Effect of A. fumigatus infection on the lysosomal cysteine proteases activities}

After fungal infection, the activity level of CPL observed significantly very high ( 2 fold) in infected group (I) while its level found decreased in animal treated with antifungal compounds (DHP and AmpB) compared to wild-type and negative control animals (Fig 2a). Similarly the activity level of CPB increased very high after infection and found decreased in their activity (more than 3 folds) in antifungal compounds treatment (Fig 2c). Surprisingly only in the case of $\mathrm{CPB}$, we also observed elevation in the activity level of $\mathrm{CPB}$ in negative control (treated with cortisone only, an immune-suppressant) animals which is almost equally high as in infected group (I) when compared with wild-type control. Though it's not clear why the level of CPB got altered after use of immune-suppressant but on the basis of published reports [21] we predict that after infection, fungus also release some toxins that suppress the immune system which may responsible to maintain the CPB level, and results appearance of same activity level in both groups (2 and 3). To answered the question whether this change in activity profile of these enzymes due to fungal infection is only at activity level or it also effect the protein level, we also observed the protein expressions of these enzymes (cathepsin B and L) in all treated and non-treated lung samples by using western blots. Like the activity profiles of these enzymes, protein expression levels were also found very much similar for both enzymes i.e. for cathepsin B and $\mathrm{L}$ (Fig $2 \mathrm{~b}$ and $2 \mathrm{~d}$ ) in all groups of mice. In other words, immunoblotting further confirms our activity findings. Furthermore, as shown in fig $2 \mathrm{e}$, we observed slightly decreased in the activity level of CPC in infected group compared to wild-type and negative control. Moreover after antifungal treatment the activity level of CPC was not showing any significant difference from the level of infected group. Similarly we also didn't observe any alteration in $\mathrm{CPH}$ activity level in the lung lysosomal fractions of all five groups of the animals (data not shown). We used acid phosphatase as a marker for confirmation of lysosomal fractions and also tried to omit any chance of impurity with fungal secretary proteases. Fig $2 f$ showed the activity profile of acid phosphatase which depicts that our work was done only with lysosomal fractions of the lung tissue.

TABLE 1: VARIOUS GROUPS OF ANIMALS AND THEIR TREATMENTS

\begin{tabular}{|l|l|l|}
\hline $\begin{array}{l}\text { Group of } \\
\text { Animals }\end{array}$ & Treatment & $\begin{array}{l}\text { Symbol Used in } \\
\text { Figures }\end{array}$ \\
\hline Group 1 & $\begin{array}{l}\text { Wild-type control } \\
\text { (Normal) }\end{array}$ & WT \\
\hline Group 2 & $\begin{array}{l}\text { Mice treated with } \\
\text { Cortisone, Negative } \\
\text { Control }\end{array}$ & NC \\
\hline Group 3 & $\begin{array}{l}\text { Mice infected with } \text { A. } \\
\text { fumigates (Aspergillosis } \\
\text { Model), Infected group, } \\
\text { Positive Control }\end{array}$ & I \\
\hline Group 4 & $\begin{array}{l}\text { Aspergillosis model treated } \\
\text { with DHP }\end{array}$ & DHP \\
\hline Group 5 & $\begin{array}{l}\text { Aspergillosis model treated } \\
\text { with AmpB }\end{array}$ & AmpB \\
\hline
\end{tabular}

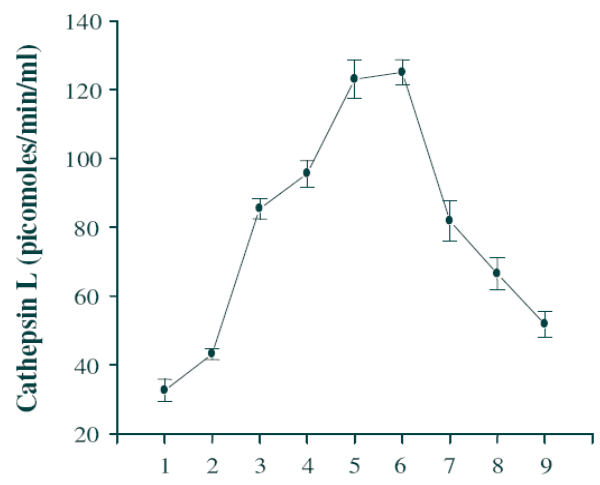

Fig.1. Activity levels of CPL in the A. fumigatus infected mouse lung. The expression of cathepsin $\mathrm{L}$ was optimum on 6 th day. Mice $(n=6)$ were sacrificed every day to measure the CPL activity level in lungs.
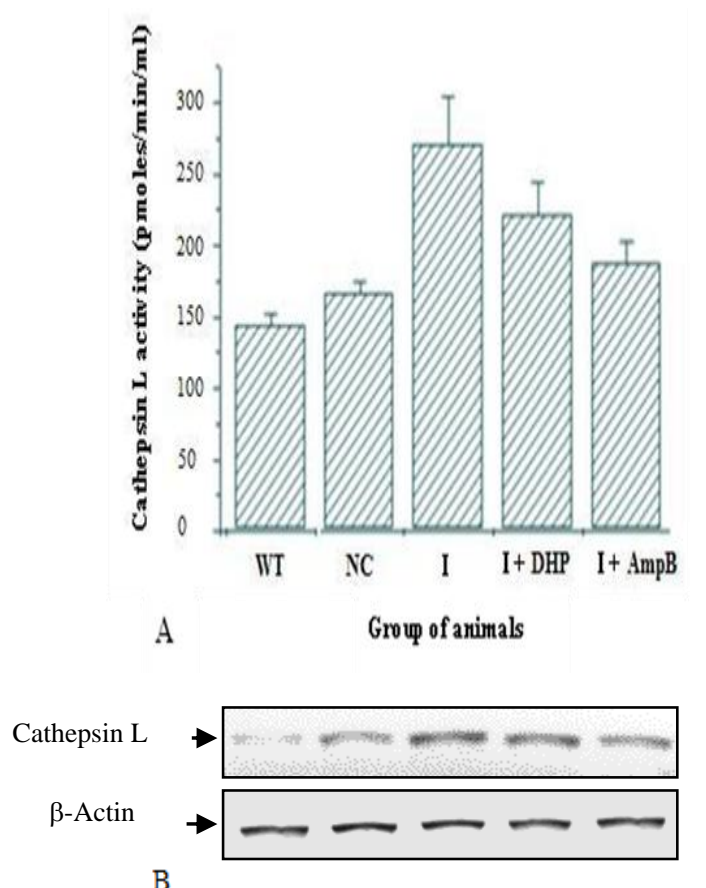

B

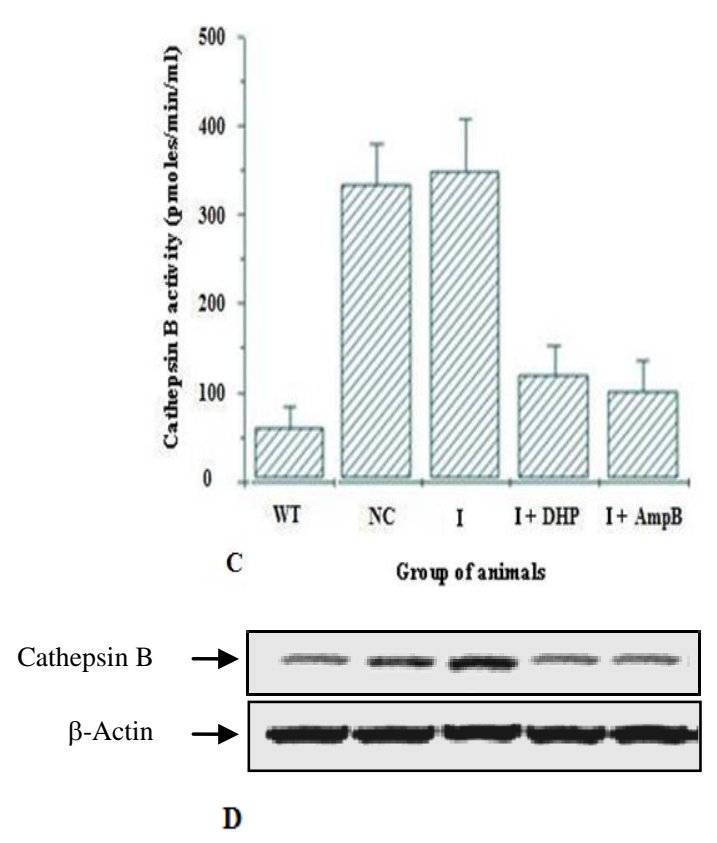



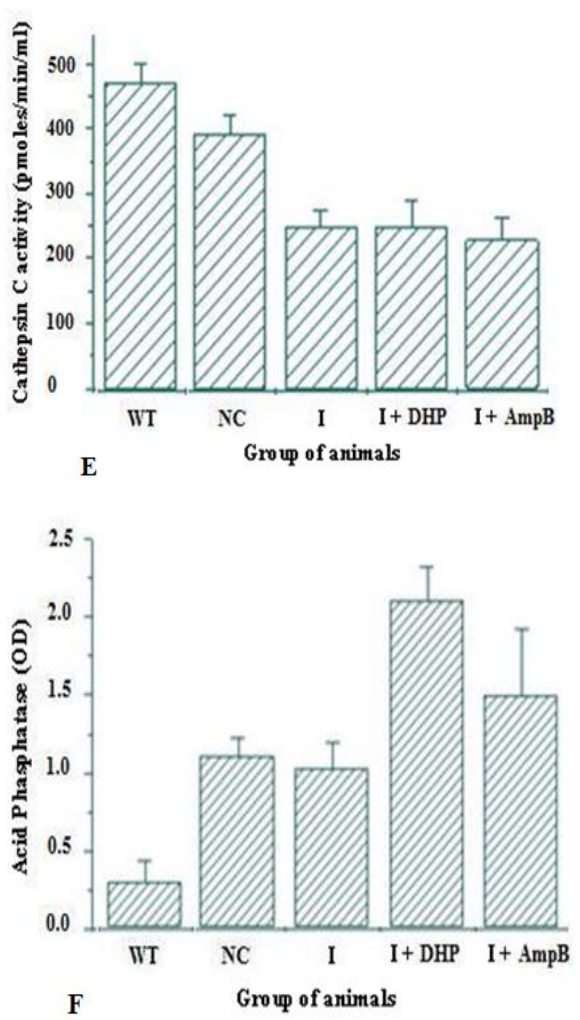

Fig 2. The effect of A. fumigates and antifungal compounds on cysteine proteases activities in each experimental group ( $\mathrm{n}=9$ ) (WT, wild-type control; NC, negative control; I, infected group, I+DHP \& I+AmpB, after fungal infection treatment with antifungal compounds) were measured and expressed in pmoles $/ \mathrm{min} / \mathrm{ml}$. (A \& C) Represent the activity levels for CPL \& CPB in each group of mice respectively; (B \& D) Represents the CPL $\&$ CPB protein expression in all groups of mice (as explained in Table1). Results were analyzed by western immunoblot by using CPL \& CPB antibodies respectively; (E) Represents the activity level for CPC and; (F) acid phosphatase activity (a lysosomal marker).

\section{Alteration in the level of IL-4 and IFN- $\gamma$ in antifungal compound treated group}

Some cytokines (IL-4 and IFN- $\gamma$ ) are well reported to be involved in fungal mediated infections and play the essential role in immune-functional differentiation. To see the effect of A. fumigatus on these cytokines levels in our experimental model, we also studied the profiles of these cytokines in all five groups. As shown in fig $3 \mathrm{a}$ and fig $3 \mathrm{~b}$, the animals infected with $A$. fumigatus conidia and then treated with antifungal compounds (AmpB and DHP) were found decreased in the levels of IL-4 significantly i.e. approximately 4 folds while observed elevation in IFN- $\gamma$ compared with infected group (group 3).

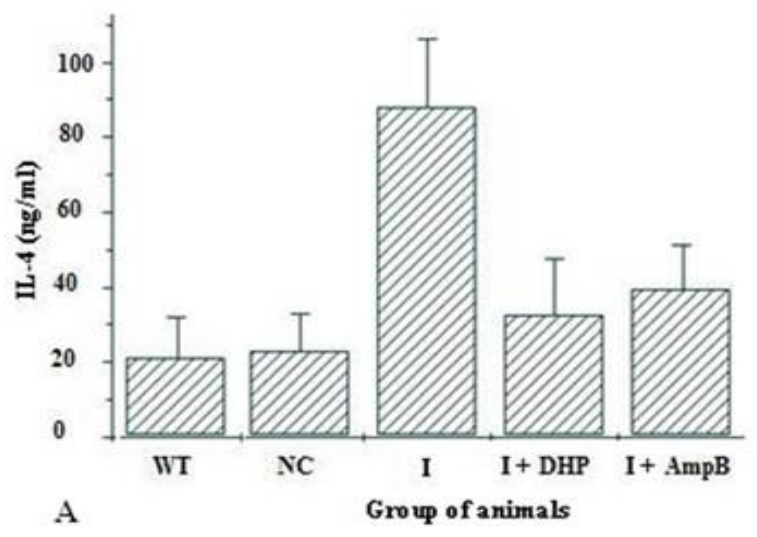

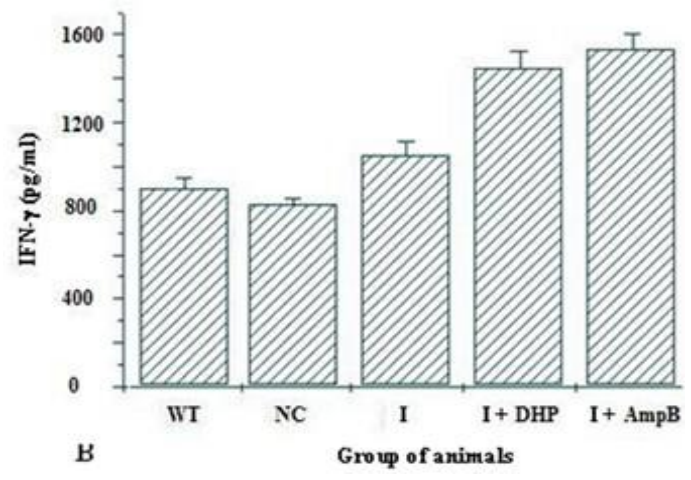

Fig. 3. The expression levels of IL-4 and IFN-in various groups were measured and represented in $\mathrm{ng} / \mathrm{ml}$ and $\mathrm{pg} / \mathrm{ml}$ respectively. (A) Represents the IL-4 levels and (B) Represents the IFN- $\gamma$ level in the blood samples from each experimental mice group.

\section{DISCUSSION}

There are many reports on the immune system impaired by A. fumigatus but scarcity of data is available related to its interaction with tissue lysosomal cysteine proteases. Cysteine proteases are very well reported in lung disorders $[22,23]$. Therefore, the data of the present study provides strong evidence for relationship between lung tissue lysosomal cysteine protease and Aspergillosis.

\section{A. Fumigates induces Alteration in the Cysteine Protease Activity}

As reported in various disorders, we also found an increased in the CPL and CPB activities in the lung tissues of A. fumigatus infected mice compared to control. However after treatment with antifungal compounds i.e. DPH and AmpB, we observed 3-fold significant ( 3 folds) reduction in CPB activity (Fig 2c). While, at the same time both compounds were found to stabilize the increased activity of CPL as compared to the negative controls (Fig 2a). In other words, slightly decreased in CPL activity was observed after antifungal compound treatment. This decrease in the activities of CPB and CPL indicates the importance of these enzymes and more specifically for CPB in host defense system against $A$. fumigates mediated disease. These results were also confirmed by western blot (Fig 2b and d) which further explain the regulatory effect of cathepsins in fungal infections. Furthermore, the activity level of other cysteine protease i.e. CPC, was found low in all groups of infected mice (treated as well) as compared to wild-type and negative control groups (Fig 2e). Through this CPC data, it's very hard to explore any direct relation between fungal disease and CPC but decreased in the activity level of CPC illustrates the possibility of its involvement as an essential component of immune system. It is also possible that fungal $\mathrm{sp}$ may secret some irreversible inhibitors for this type of proteases which inactive the enzymes even in presence of antifungal compounds. Similar to our study, other research groups also explained that CPC deficiency results in considerably milder immune deficiency [24]. Study on another cysteine protease i.e. cathepsin $\mathrm{H}$ activity level was found normal in all groups of mice (Data not shown). This present available cathepsins data explored the possibility of a relation between lysosomal cysteine proteases and fungal infection. 
CPB was found more effective in A. fumigatus mediated disease progression and regulation of activity of CPB could be effective in fungal treatment. This existence of lysosomes enzyme was further confirmed by the level of acid phosphatase (Fig 2f) which suggest that lysosomal activity is playing an essential role in fungal infection.

\section{B. Fumigates induces Alteration in the Cytokines Profiles}

Acute invasive aspergillosis is challenging disease because of involvement of various confounding factors including cytokines. Some cytokines may have beneficial or deleterious effect on fungal infection. Specifically, Th1 and Th2 pathways directly relate to the severity of infection. Th1-produces cytokines (IFN- $\gamma$ ) activate macrophages, the key effectors in invasive aspergillosis whereas Th2 cytokine, IL-4 has worse outcome [9]. According to available evidence, IL-4 knock-out mice show deficient Th2 response and found more resistant to infection [9]. In continuation of this, we further confirm these findings in our experimental models by observing the profile of cytokines (IFN- $\gamma$ and IL-4) in presence of $A$. fumigates and antifungal compounds. As shown in figure $3 \mathrm{a}$, after infection, the level of IL-4 was increased very significantly while in presence of antifungal compounds it comes to the level of control. However, the level of IFN $\gamma$ (Figure 3b) is behaving opposite to IL-4 under both conditions. Importantly, these alterations in the pattern of cytokines levels correspond to the change in the CPB activity profile (Figure 2c). Furthermore, lysosomal cysteine proteases are also known to be involved in the antigen processing and in differentiation of functional $\mathrm{CD}^{+} \mathrm{T}$ cell subsets [25]. By using various cysteine protease specific inhibitors, the roles of CPB and CPL are well established in immune system. CPB inhibitor CAO74 was reported to change the digestion pattern of lysosomal enzyme and modulate the immune response from Th2 type to Th1 type [26]. On the other hand inhibitor of CPL potentiates Th2 type immune response [27]. Overall, to our present findings, we observed decrease in the lysosomal CPB activity and IL4 level while increased in the IFN- $\gamma$ level in presence of antifungal compounds (AmpB and DHP) which indicates the possibility in modulation of immune response from Th2 type to Th1 type. Additionally, from cancer research [28, 29] it's always observed decreased immunity of the patient and result increase in the chance of fungal infection and also found elevation in the CP and IL-4 levels without any correlation among them. From our present study, it is possible to predict about these changes. We are hypothesizing that after fungal infection, alteration in the cathepsins levels occur which may involve in tissue remodeling and result affect the surfactant proteins such as IL-4 that further alter the person immunity. Therefore, use of cancer medicines and antifungal drugs along with antithiol protease may be a beneficial combitorial therapy approach for cancer patients.

\section{CONCLUSIONS}

In recent years, various approaches have been made to eradicate the Aspergillosis. Despite significance advancement in antifungal therapies, overall mortality rate is still very high. Importantly, early diagnosis is difficult because of lack of desired specificity and sensitivity approaches. In our study, we found CPB specificity towards A. fumigatus mediated infection which increased with fungal infection and decreased with antifungal treatment vary significantly. By studying the activity as well as immunoblotting profiles of CPB, we could use this enzyme for early diagnosis purpose and possibly it can be used as a therapeutic target for aspergillosis. In summary, a correlation between cysteine protease and fungal infection was observed which opens a new paradigm for tissue lysosomal enzymes in fungal mediated diseases. Further studies need to be done to characterize other specific cysteine protease and also needs to elaborate the characterization of CPB in fungal infections.

\section{REFERENCES}

[1] M.D. Richardson. Changing pattern and trends in systemic fungal infections. J. Antimicrob. Chemotherp. vol 56, 2005, pp. i5-i11.

[2] J. Behnsen, F. Lessing, S. Schindler, D. Wartenberg, et al. Secreted Aspergillus fumigatus protease Alp1 degrades human complement proteins C3, C4, and C5. Infect Immun. vol 78, 2010, pp. 3585-3594.

[3] J.P. Latge. Aspergillus fumigatus and aspergillosis. Clin. Microbiol. Rev. vol 12, 1999, pp. 310-350.

[4] C. Lefebvre, F. Vandenbulcke, B. Bocquet, et al. Cathepsin L and cystatin B gene expression discriminates immune coelomic cells in the leech Theromyzon tessulatum. Dev Comp Immunol. vol 32, 2008, pp. 795-807.

[5] C. Serveau-Avesque, MF Martino, V Hervé-Grépinet, et al. Active cathepsins B, H, K, L and S in human inflammatory bronchoalveolar lavage fluids. Biol Cell. vol. 98, 2006, pp. 15-22.

[6] V. Turk, B. Turk, D. Turk. Lysosomal cysteine proteases: facts and opportunities. EMBO J. vol. 20, 2001, pp. 4629-4633.

[7] Y. Yang, J.B. Waters, R. Fruh, P.A. Peterson. Proteasomes are regulated by interferon gamma: implications for antigen processing. PNAS, USA. vol. 89, 2001, pp. 4928-4932.

[8] V. Steimic, C.A. Siegrist, A. Mottet, B. Lisowska-Grospierre, B. Mach. Regulation of MHC class II expression by interferon-gamma mediated by the transactivator gene CIITA. Science. vol. 265, 1994, pp. 106-108.

[9] H. Sambatakou, V. Pravica, V. Hutchinson and D.W. Denning. Cytokines profiling of pulmonary aspergillosis. Int. J immunogenetics. vol. 33, 2006, pp. 297-302.

[10] R. Dabur, S.K. Diwedi, V. Mishra, V. Yadav et al. In vivo efficacy of 2-(3, 4-dimethyl-2, 5-dihydro-1H-pyrrol-2-yl)-1-methylethyl pentanoate, in mice model of invasive aspergillosis. Antimicrob. Ag. Chemotherap. vol. 49, 2005, pp. 4365-4367.

[11] R. Dabur, H. Singh, M. Ali and G.L. Sharma. A novel antifungal pyrrole derivative from Datura metel leaves. Pharmazie. vol. 59, 2004, pp. 568-570.

[12] D.M. Dixon, A. Polak, T.J. Walsh. Fungus dose-dependent primary pulmonary aspergillosis in immunosuppressed mice. Infect Immun. vol. 57, 1989, pp. 1452-1456.

[13] E. Cohen, R. Atzmon, I. Vlodavsky, N. Ilan. Heparanase processing by lysosomal/endosomal protein preparation. FEBS Lett. vol. 579, 2005, pp. 2334-2338.

[14] R.C. Kamboj, N. Raghav, A. Mittal, S. Khurana, R. Sadana, H. Singh. Effects of some Antituberculous and Anti-Leprotic Drugs on Cathepsins B, H and L. Ind J Clinical Biochem, vol. 18, 2003, pp 3947.

[15] S. Pal, N. Raghav, R.C. Kamboj and H. Singh. Res. Bull. Panjab Univ. (India). vol. 51, 2001, pp. 41-59.

[16] T. Zhang, DM Rawson, L. Tosti, O. Carnevali. Cathepsin activities and membrane integrity of zebrafish (Danio rerio) oocytes after freezing to -196 degrees $\mathrm{C}$ using controlled slow cooling. Cryobiology. vol. 56, 2008, pp. 138-143.

[17] R. Sadana, Mittal A, S. Khurana, H. Singh \& RC Kamboj, Purification and characterization of cathepsin L-like proteinase from goat brain, Ind J Biochem Biophys, vol. 40, 2003, pp. 315-323.

[18] S. Shiloko, A.L. Tappel. Acid phosphatase of the lysosomal and soluble fraction of rat liver. Biochim. Biophys. Acta. vol. 73, 1963, pp. 76-80.

[19] R. Goyal, A. Mittal, N. Chu, R.A. Arthur, L. Zhang, L.D. Longo. Maturation and long-term hypoxia-induced acclimatization responses 
in PKC-mediated signaling pathways in ovine cerebral arterial contractility. Am J Physiol Regul Integr Comp Physiol. vol. 299(5), 2010, pp. R1377-86.

[20] O.H. Lowry, N.J. Rosebrough, A.L. Farr, R.J. Randall. Protein measurement with the Folin phenol reagent. J Biol Chem. vol. 193(1), 1951, pp. 265-75.

[21] M. Stanzani, E. Orciuolo, R. Lewis, D.P. Kontoyianni et al. Aspergillus fumigatus suppresses the human cellular immune response via gliotoxin-mediated apoptosis of monocytes. Blood. vol. 105, 2005, pp. 2258-2265.

[22] P.J. Wolters, H.A. Chapman. Importance of lysosomal cysteine proteases in lung disease. Respir Res. vol. 1, 2000, pp. 170-177.

[23] F. Bühling, N. Waldburg, A. Reisenauer, A. Heimburg, H. Golpon, T. Welte. Lysosomal cysteine proteases in the lung: role in protein processing and immunoregulation. Eur Respir J. vol. 23, 2004, pp. 620-628.

[24] V.R. Sutton, N.J. Waterhouse, K.A. Browne, et al. Residual active granzyme $\mathrm{B}$ in cathepsin $\mathrm{C}$-null lymphocytes is sufficient for perforin-dependent target cell apoptosis. J. Cell. Biol, vol. 176, 2007, pp. 425-433.

[25] T.L. Tamara, M. Hawley, K.L. Rock, A.L. Goldberg. Gammainterferon causes a selective induction of the lysosomal proteases, cathepsins B and L, in macrophages, FEBS Letters. vol. 363, 1995, pp. 85-89.

[26] Y. Maekawa, K. Himeno, H. Ishikawa, H. Hisaeda, T. Sakai, et al. Switch of CD4+ T cell differentiation from Th2 to Th1 by treatment with cathepsin B inhibitor in experimental leishmaniasis. J. Immunol., vol. 161, 1998, pp. 2120-2127.

[27] T. Zhang, Y. Maekawa, T. Sakai, Y. Nakano, K. Ishii, et al. Splenic cathepsin $\mathrm{L}$ is maturated from the proform by interferon $\gamma$ after immunization with exogenous antigens. Biochem. Biophys. Res. Commun. vol. 283, 2001, pp. 499-504.

[28] N. Sohrabi, A.R. Khosravi, Z.M. Hassan, M. Mahdavi, A.A. Amini, M. Tebianian. Effect of Invasive Aspergillosis Infection on the Immune Responses of Cancer Mice. Iran J. Basic Med. Sci, vol. 11, 2009, pp. 242-249.

[29] A.M. Szpaderska and A. Frankfater. An Intracellular Form of Cathepsin B Contributes to Invasiveness in Cancer. Cancer Research. vol. 61, 2001, pp. 3493-3500.

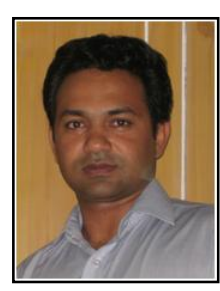

Ashwani Mittal was born in Kurukshetra, Haryana, India. He did his B.S. (1997) and M.S. (1999) in Biochemistry from Kurukshetra University, Kurukshetra. In April 2005, he received a PhD degree in Protein Biochemistry from the Department of Biochemistry of Kurukshetra University. From October 2003 to till date, he has been serving the Kurukshetra University as an Assistant Professor of Biochemistry. From March 2007 to August 2009, he was awarded with a Post-doctoral fellowship under a combined project from the University of Loma Linda and from University of Louisville, USA in the field of Skeletal and Smooth Muscle Biology. His current research interests are included Protein Biochemistry, Skeletal Muscle
Physiology. Presently he has been working with natural compounds and studying their effects under various pathological conditions including Skeletal Muscle Loss etc. He published more than 20 research papers in national/international journals and conferences.

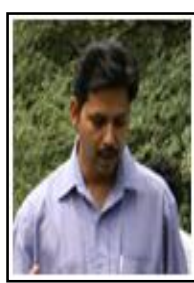

TK Mandal did his B.A.M.S. from University of Culcutta, India in 1995. Thereafter he completed his MD (Ayurveda) in Dravyaguna Medicinal Plants in 2001 from Banaras Hindu University (BHU), India. In 2006, he received his $\mathrm{PhD}$ from same university (BHU), India. Later on he joined at National Institute of Basic Ayurvedic Sciences, Pune, India as a Research Officer. His area of specializations includes Clinical, Experimental \& Literary Research on Indian Medicinal Plants. In 2007, he published a book on Database of Important Medicinal Plants, Volume-VIII. CCRAS Press, Govt of India, New Delhi. He has published several research papers in national and international journals.

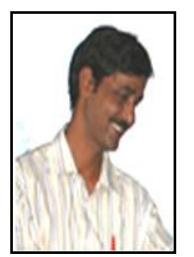

Rajesh Dabur did his M.S. (1995) in Biochemistry from Kurukshetra University, Kurukshetra. In 2001, he received a $\mathrm{PhD}$ degree from the Department of Biochemistry of Kurukshetra University, Kurukshetra and IGIB (CSIR), Delhi. From August 2001 to January 2003, he worked as a Post-doctoral Fellow in the City of Hope, Duarte, CA and Harvard, Boston, MA, USA in the field of Structure Biology. From August 2003 to January 2006, he served the Bundelkhand University, Jhansi, India, as a Lecturer of Biochemistry. Later on he joined at National Institute of Basic Ayurvedic Sciences, Pune, India as a Research Officer. He published two books i.e. "Construction of Ordered protein Arrays", Academic Press, Inc. A Division of Harcourt Brace \& Company, 525 B Street, Suite1900,San Diego, California, 92101-4495 and "Database of Important Medicinal Plants", Volume-VIII. CCRAS Press, Govt of India, New Delhi. Besides this, he has four patents in his credit, out of that one patent is from USA, one from Europe and rest two are Indian patents. He has published more than 25 research papers in national as well as international journals and conferences around the world, and also has given various invited talks/lectures at conferences and universities/Institutes around the India. Presently, his group is focusing on various projects including; Studies on Structural and Functional Aspects of Human Telomeric RNA proteins, Functional Genomics and Proteomics of Ayurvedic Management of Obesity with special reference to Tridosha Prakriti Concept etc.

Rajat Bindal recently did his B.Tech (2010) in Biotechnology from Seth Jai Parkash Mukund Lal, Institute of Engg. \& Technology, Radaur, Kurukshetra University, Kurukshetra, Haryana, India. He was a student of this institute from 2006 to 2010 . 